\title{
ARTICLE \\ Hope, coping and psychosocial adjustment after spinal cord injury
}

\author{
Pat Dorsett ${ }^{1}$, Timothy Geraghty ${ }^{2}$, Anne Sinnott ${ }^{3}$ and Rick Acland ${ }^{4}$
}

\begin{abstract}
INTRODUCTION: The study was a prospective, longitudinal design. The purpose was to explore the role of hope in the coping and psychosocial adjustment process following a spinal cord injury. The study was conducted at Spinal cord injury rehabilitation units in Queensland, Australia and Christchurch, New Zealand.

MATERIALS AND METHODS: This was a longitudinal study conducted in two SCl rehabilitation centres, one in Australia and one in New Zealand. A total of 47 participants with newly acquired traumatic SCl were administered a survey consisting of the Adult Hope Scale; the Moorong Self-Efficacy Scale; the Centre for Epidemiology Studies-Depression Scale (CES-D); Life Satisfaction, Self-Rated Adjustment and Life Problems Subscales of the Life Situation Questionnaire and selected subscales from the Spinal Cord Lesionrelated Coping Strategies Questionnaire (SCL-CSQ) and the COPE scales at 6 weeks post injury and 3 months post discharge. RESULTS: Hope levels and coping strategies remained consistent over time. Hope levels significantly and positively correlated with life satisfaction and self-reported adjustment, and negatively correlated with life problems. Hope levels also positively correlated with positive coping styles, including positive reappraisal, planning, acceptance and fighting spirit. Finally, hope levels negatively correlated with the negative coping strategies behavioural disengagement and social reliance.

DISCUSSION: Hope and coping styles are likely to be determined by personality traits. The findings suggest that hope enhancing interventions should be explored as a means of improving outcomes for people with SCl.
\end{abstract}

Spinal Cord Series and Cases (2017) 3, 17046; doi:10.1038/scsandc.2017.46; published online 21 September 2017

\section{INTRODUCTION}

Spinal cord injury $(\mathrm{SCl})$ results in a sudden and profound disruption to an individual's life. This sudden and profound disruption creates stressors in all aspects of a person's life. ${ }^{1}$ The stresses encountered are considerable, especially when the uncertainties created by $\mathrm{SCl}$ are taken into account. The individual then engages in coping efforts to manage these stressors. Thus a critical factor underpinning psychosocial adjustment involves (in part) the coping capacity of the individual. ${ }^{2-5}$ Thus, a critical factor underpinning psychosocial adjustment involves (in part) the coping capacity of the individual.

Research demonstrates that psychosocial adjustment outcomes occur along a continuum. It is reported that the majority of people who sustain $\mathrm{SCl}$ are able to achieve positive psychological outcomes and generally report a satisfying quality of life. ${ }^{6-8}$ However a minority of people with $\mathrm{SCl}$ do not achieve positive adjustment outcomes, with between 25 and 38\% experiencing elevated levels of depression and anxiety and reduced quality of life outcomes. ${ }^{8-10}$

While there are many factors that impact psychosocial adjustment following $\mathrm{SCl}$, it has been suggested that some coping strategies are linked with more positive outcomes. For example, Elfstrom et al. ${ }^{11,12}$ found that the coping styles acceptance (that is, revaluation of life values) and fighting spirit (that is, efforts to minimise the effects of the injury) were positively correlated with better adjustment outcomes following $\mathrm{SCl}$; whereas the coping response of social reliance (that is, tendency towards dependent behaviour) was associated with more psychological distress.
Other authors have reported that the coping strategy 'behavioural disengagement' was correlated with poor psychological adjustment, increased distress and deteriorating health outcomes, while 'acceptance' and 'positive reinterpretations' were associated with better outcomes and lower levels of distress. ${ }^{13-17}$

Hope has been identified as an important facilitator of adjustment following $\mathrm{SCl}^{18}$ This finding is somewhat counter intuitive and challenges traditional rehabilitation approaches that suggest that it is important for a person with $\mathrm{SCl}$ to accept his/her limitations to maximise rehabilitation outcomes. ${ }^{1,4,19}$ Indeed, recent findings suggest that contrary to the traditional perspective, high hope, even false hope, is associated with lower levels of depression, greater acceptance of disability, increased life satisfaction, less perceived stigma, increased mobility and fewer participation restrictions. ${ }^{6,20}$ Increasingly, empirical evidence suggests that hope may have a buffering and resource replenishing function, facilitating better psychosocial adjustment and rehabilitation outcomes. ${ }^{21,22}$ Folkman $^{22}$ argues that hope underpins all coping efforts in challenging health contexts, with a dynamic and reciprocal relationship between hope and coping. She argues that hope plays a crucial role in sustaining coping efforts, as people strive to deal with the stresses and uncertainty created by circumstances such as sustaining a $\mathrm{SCl}$.

Hope is increasingly recognised as an important coping strength and an appropriate target for clinical intervention in $\mathrm{SCl}$ rehabilitation settings. ${ }^{18,23}$ Dorsett $^{18}$ reported that more than $70 \%$ of people with $\mathrm{SCl}$ in a qualitative study identified hope as an important factor contributing to their adjustment outcome.

\footnotetext{
${ }^{1}$ School of Human Services and Social Work, Griffith University, Logan Campus, University Drive, Meadowbrook, Queensland, Australia; ${ }^{2}$ Queensland Spinal Cord Injuries Service, The Hopkins Centre: Research for Rehabilitation and Resilience, Princess Alexandra Hospital, Metro South Health, Wooloongabba, Queensland, Australia; ${ }^{3}$ Burwood Academy of Independent Living, University of Otago, Christchurch, New Zealand and ${ }^{4}$ Burwood Spinal Unit, Christchurch, New Zealand.

Correspondence: Dr P Dorsett (p.dorsett@griffith.edu.au)

Received 16 December 2016; revised 15 June 2017; accepted 28 June 2017
} 
Given the increasing evidence of the value of hope in the adjustment process, it is important to develop a better understanding of the links between hope and coping, and their potential to inspire new interventions that support adjustment. To date, research investigating the role of hope in the coping and adjustment processes following $\mathrm{SCl}$ has been limited.

The aim of this study was to investigate the impact of hope on coping and subsequent psychosocial adjustment outcomes in a $\mathrm{SCl}$ sample. It was hypothesised that people with $\mathrm{SCl}$ and higher hope would:

1. Have better psychosocial adjustment outcomes than those with lower hope.

2. Be more likely to utilise positive coping strategies such as acceptance, fighting spirit and positive reinterpretation.

3. Be less likely to use less effective coping strategies such as social reliance or behavioural disengagement.

\section{MATERIALS AND METHODS}

\section{Design}

This study utilised a prospective longitudinal design. A survey consisting of a series of standardised and validated measures was administered at $6-8$ weeks post injury (Time 1 ) and again at 3 months post discharge from initial rehabilitation (Time 2).

\section{Participants}

Participants were recruited from the Queensland Spinal Cord Injuries Service (QSCIS), Brisbane, Australia and the Burwood Spinal Cord Injuries Unit, Christchurch, New Zealand. All patients over the age of 18 years admitted with acute traumatic SCl were eligible and invited to participate in the study. Patients who were unable to provide informed consent, deemed medically or psychologically unfit or were not available for followup at 3 months post discharge were excluded.

During the 16-week recruitment period, 28 eligible patients were admitted to the QSCIS and invited to participate in the study. Three declined. Thirtyone eligible patients were admitted to the Burwood Spinal Injuries Unit and nine declined to participate. Thus the final sample consisted of 25 Australian and 22 New Zealand participants giving a total sample of 47 participants. Participants consisted of 36 men and 11 women ranging in age from 20 to 72 years $(M=45.67$, s.d. $=15.30)$. The sample represents approximately onethird of the QSCIS annual traumatic admissions and about half of the Burwood Spinal Cord Injuries Unit annual traumatic admissions. Sample demographics are presented in Table 1. There was a participant attrition rate of $29 \%(n=14)$ resulting in a final sample of 33 at Time 2 .

\section{Measures}

Hope measures. The adult version of Synder's Hope Scale $(\mathrm{HS})^{24,25}$ is a 12 -item self-report inventory measuring hope levels across two domains; agency (goal-directed energy) and pathways (planning to meet goals). Each subscale comprises of four items, with the remaining four items as fillers, which are discarded for score calculation. Items are arranged on four-point Likert type scales (from $1=$ 'definitely false' to $4=$ 'definitely true') and calculated as a sum of these item scores, with scores ranging from a low of 4 to a high of 16 for each subscale and an overall score of 8-32. Higher scores indicate a higher level in each domain. The HS has a high level of reliability with reported Cronbach's alpha ranging from 0.74 to 0.84 .The current study was consistent with this $(0.71$, with subscales ranging from 0.77 to 0.79$)$. The scale has a high level of concurrent validity with other scales tapping similar constructs such as hopelessness and positive life expectancy.

Outcome measures. The Moorong Self-Efficacy Scale (MSES) ${ }^{27,28}$ is a $\mathrm{SCl}$-specific measure of self-efficacy incorporating 16 items graded along a seven-point Likert scale assessing participants' certainty of managing difficulties related to their injuries (from $1=$ 'very uncertain' to $7=$ 'very certain'). Scores are summed to give an overall score ranging from 16 to 112. Higher scores indicate higher levels of self-efficacy. MSES has been found to have acceptable reliability and validity, with Cronbach's alphas ranging from 0.87 to $0.95,{ }^{27-29}$ consistent with a present sample alpha of 0.95 .
Table 1. Participant demographic and injury characteristics $(n=47)$

\begin{tabular}{|c|c|c|c|}
\hline & $\begin{array}{c}\text { Australia } \\
(\mathrm{n}=25) \\
\text { Number (\%) }\end{array}$ & $\begin{array}{c}\text { New Zealand } \\
(\mathrm{n}=22) \\
\text { Number (\%) }\end{array}$ & $\begin{array}{l}\text { Total }(\mathrm{n}=47) \\
\text { Number }(\%)\end{array}$ \\
\hline \multicolumn{4}{|l|}{ Gender } \\
\hline Male & $20(80 \%)$ & $16(73 \%)$ & 36 (77\%) \\
\hline Female & $5(20 \%)$ & $6(27 \%)$ & $11(23 \%)$ \\
\hline \multicolumn{4}{|l|}{ Age at injury } \\
\hline $20-29$ yrs & $5(20 \%)$ & $4(18 \%)$ & $9(19 \%)$ \\
\hline $30-39$ yrs & $5(20 \%)$ & $4(18 \%)$ & $9(19 \%)$ \\
\hline $40-49$ yrs & 7 (28\%) & 0 & 7 (15\%) \\
\hline $50-59$ yrs & $4(16 \%)$ & $10(45 \%)$ & $14(30 \%)$ \\
\hline $60-69$ yrs & $4(16 \%)$ & $3(14 \%)$ & $7(15 \%)$ \\
\hline $70+$ yrs & 0 & $1(5 \%)$ & $1(2 \%)$ \\
\hline Range & $22-69$ & $20-72$ & $20-72$ \\
\hline Mean (median) & $44(42)$ & $47.5(52)$ & 45.7 (47) \\
\hline \multicolumn{4}{|l|}{ Level of injury } \\
\hline Tetraplegia & $14(56 \%)$ & 15 (68\%) & $29(62 \%)$ \\
\hline Paraplegia & 11 (44\%) & 7 (32\%) & $18(38 \%)$ \\
\hline \multicolumn{4}{|l|}{ American Spinal Injury } \\
\hline \multicolumn{4}{|l|}{ Association (ASIA) } \\
\hline \multicolumn{4}{|l|}{ Impairment Scale } \\
\hline A & $12(48 \%)$ & $11(50 \%)$ & $23(49 \%)$ \\
\hline B & $6(24 \%)$ & $5(23 \%)$ & $11(24 \%)$ \\
\hline C & $5(20 \%)$ & $5(23 \%)$ & $10(21 \%)$ \\
\hline D & $2(8 \%)$ & $1(4 \%)$ & $3(6 \%)$ \\
\hline \multicolumn{4}{|l|}{ Aetiology } \\
\hline Road trauma & 12 (48\%) & $4(18 \%)$ & 16 (34\%) \\
\hline Falls & $3(12 \%)$ & $5(23 \%)$ & $8(17 \%)$ \\
\hline $\begin{array}{l}\text { Sports/recreational } \\
\text { activity }\end{array}$ & $4(16 \%)$ & $8(14 \%)$ & $12(26 \%)$ \\
\hline Acts of violence & $2(8 \%)$ & 0 & $2(4 \%)$ \\
\hline Other & $4(16 \%)$ & $5(36 \%)$ & $9(19 \%)$ \\
\hline
\end{tabular}

The Life Situation Questionnaire (LSQ) ${ }^{30-32}$ is a SCl-specific measure of rehabilitation and adjustment outcomes, and consists of several subscales. Three subscales of the LSQ were used in the study; the life satisfaction (11 items); problems of life (14 items); and self-rated psychosocial adjustment subscales. The life satisfaction and problems of life subscales are scored on a five-point Likert scale where $1=$ 'very satisfied' or 'no problems' and $5=$ 'very dissatisfied' or 'major problems'. Scores are summed with higher scores indicating less satisfaction and more problems, respectively. Scores range from 11 to 55 and 14 to 70 for the satisfaction and problem scales, respectively. The self-rated adjustment scale asks participants to rate their adjustment on an ascending scale out of 10, with 10 representing the best possible outcome. The LSQ has a high level of validity and reliability, with reported Cronbach's alpha ranging from 0.79 to $0.92,{ }^{30-32}$ and alphas for the present sample subscales ranging from 0.90 to 0.93 .

The Center of Epidemiological Studies-Depression Scale (CES-D) is a 20 -item self-report questionnaire measuring depressive symptomology. ${ }^{33}$ Items are arranged on a Likert scale assessing frequency of symptoms $(0=$ 'rarely or none of the time' to $3=$ 'most or all of the time'). Overall scores are calculated as a summation of the item scores with higher scores indicating more depressive symptomatology, with an overall score range of $0-60 .{ }^{34}$ High internal consistency, test-retest stability and concurrent validity with other clinical evaluations and self-report criteria have been reported in samples of both general disability and SCl with Cronbach's alpha ranging from 0.84 to $0.90^{35-37}$ and 0.81 in the present study.

\section{Coping outcomes}

Two measures of coping strategies were used in this study.

The Spinal Cord Lesion-Related Coping Strategies Questionnaire $(\mathrm{SCL}-\mathrm{CSQ})^{11,12}$ is a SCl-specific scale developed to explore injury-related coping processes. The SCL-CSQ consists of 12 items measuring the utilisation of three coping strategies; acceptance (re-evaluation of life values), fighting spirit (efforts to minimise the impact of the injury) and 
social reliance (tendency to depend on others). Each subscale item is scored from $1=$ 'strongly disagree' to $4=$ 'strongly agree'. Subscale scores are the mean of these item ratings and thus range from 1 to 4 , with a higher score indicating a greater tendency towards that coping strategy. The scale has demonstrated acceptable internal validity and reliability with Cronbach's alpha ranging from 0.44 to $0.64 .^{11,12}$

The COPE is a generic coping measure, which assesses preferred coping styles as opposed to situation-specific coping strategies ${ }^{17}$ and has been successfully used with $\mathrm{SCl}$ populations. ${ }^{38}$ It consists of 60 items tapping 15 coping strategies. For this study three subscales were used: positive reinterpretation (that is, positive reappraisal, construing a stressful situation in positive terms), behavioural disengagement (that is, reducing efforts to deal with stressors or giving up) and planning (that is, thinking about actions strategies to handle a problem). Each subscale consists of four items rated from $1=$ 'I usually don't do this at all' to $4=$ 'I usually do this a lot'. Item scores are summed with higher scores indicating a higher frequency of that coping style. The COPE scale has good validity and reliability with Cronbach's alpha ranging from 0.59 to $0.79^{17}$ and subscale alphas ranging from 0.64 to 0.86 in the present sample.

\section{Procedure}

The questionnaires were administered verbally via interview. The first interview (Time 1) was conducted face-to-face in the hospital $\sim 6$ weeks post injury. The final interview (Time 2) was conducted via telephone at 3 months post discharge from hospital following initial rehabilitation. The mean time between Time 1 and Time 2 was 23.8 weeks for those participants with paraplegia and 41.2 weeks for those with tetraplegia. There was a substantial variation in the time between Time 1 and Time 2 .

\section{Statement of ethics}

This research was conducted in accordance with the Australian National Statement on Ethical Conduct in Human Research (2007). ${ }^{39}$ The study received ethical clearance and was monitored by the Griffith University Human Research Ethics Committee, and the relevant institutional ethics committees in Australia and New Zealand. All applicable institutional and governmental regulations concerning the ethical use of human volunteers were followed during the course of this research.

\section{RESULTS}

Analysis and screening

Statistical Package for the Social Sciences (SPSS, IBM Corp. IBM SPSS Statistics for Windows, Version 20.0. Armonk, NY, USA: IBM Corp.) version 20.0 was used to analyse the data from this study. Visual inspection of the data and Shapiro-Wilk tests indicated non-normal distributions for many of the variables. This was not unexpected given the small sample size of the study. Thus robust non-parametric statistical procedures were utilised where appropriate and these were noted where relevant. The majority of the sample was male (77\%), with approximately half from Australia $(n=25)$ and half from New Zealand $(n=22)$. All results reported observe an alpha level $(p)$ of 0.05 or less to be considered statistically significant.

\section{Hope scores}

Hope scores were relatively high for the overall sample at Time $1(M=26.72$, s.d. $=2.81)$ and remained consistent over time (Time 2, $M=25.91$, s.d. $=3.66)$. Although Australians $(M=25.31$, s.d. $=4.13$ ) demonstrated lower overall hope scores than New Zealand $(M=26.44$, s.d. $=3.22)$ at Time 2 (Figure 1$)$, comparison of the two samples revealed no significant differences at either time point (Time $1 t(45)=-0.11, P=0.91$; Time $2 t(32)=0.90, P=0.38$ ).

\section{Similarities between countries}

Visual inspection of the data revealed potential differences in level of depressive symptoms between the Australian and New Zealand cohorts. Inspection of Q-Q Plots and a Shapiro-Wilk test revealed that the data were normally distributed, however Levene's Test for Equality of Variances showed a violation in homogeneity of

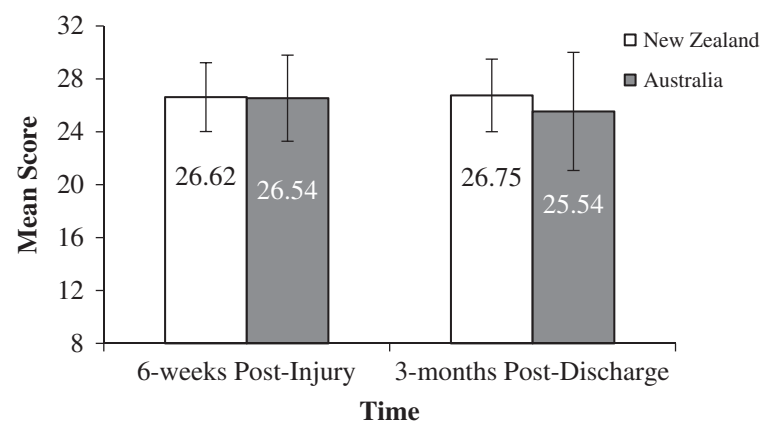

Figure 1. Mean Hope Scores (error bars denote \pm s.d.).

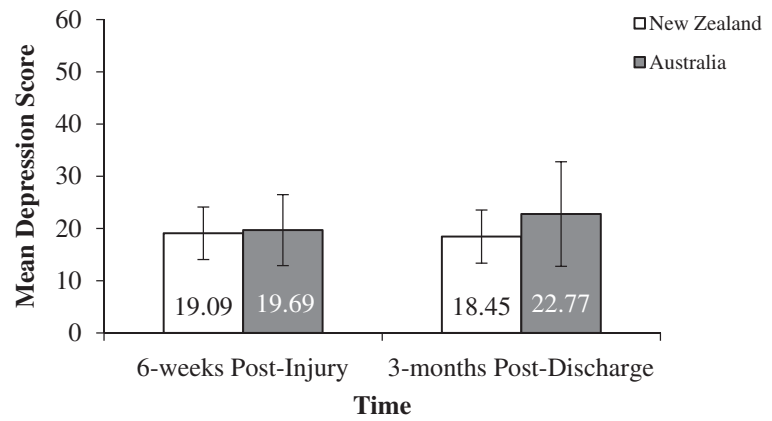

Figure 2. Mean Depression Scores over time.

variances and thus an independent samples $t$-test was performed with equal variances not assumed. Figure 2 shows the mean CES-D scores from both samples across both time points. It was noted that at Time 2 the Australian sample $(M=24.44$, s.d. $=10.13)$ demonstrated a significantly higher level of depression than the New Zealand sample $(M=16.44$, s.d. $=5.24), t(22.49)=2.81 P=0.01$. The Australian sample also demonstrated a larger s.d. at Time 2, indicating an increased variance in responses regarding depression, whereas the New Zealand sample remained relatively constant. The effect size was found to exceed Cohen's ${ }^{40}$ convention for a large effect $(d=0.80)$. Therefore, these data were analysed separately for the depression outcome variable.

The data did not significantly differ between the Australian and New Zealand cohorts on any other measure and so these data were combined for these measures to improve sample size, aid analysis and increase statistical power.

\section{Change over time}

In order to determine if there were significant changes in each variable across the two time points, paired samples $t$-tests were performed due to their robustness against minor breaches of the normality assumption. Where significance was questionable, a Wilcoxon signed rank test was performed to confirm significance of $t$ statistic due to the non-normality of the data. Scores on all variables remained stable over time, with no significant changes detected, except for behavioural disengagement, between Time 1 and Time 2 (Table 2). Effect sizes ranged from 0.003 to 0.27 , indicating a small effect.

Hope correlations

Hope and outcome variables. Spearman's correlation was used to identify the strength of relationships between hope and the outcome variables; adjustment, life satisfaction, life problems, depression and self-efficacy; at 3 months post discharge. This method was chosen over Pearson's correlation based on the nonnormality of the data. There were significant, positive correlations between HS score and MSES self-efficacy score $\left(r_{s}(32)=0.54\right.$, 
Table 2. Descriptive and paired sample $t$-test statistics for all measures across time

\begin{tabular}{|c|c|c|c|c|}
\hline Measure & $\begin{array}{l}\text { 6-8 Weeks post injury (T1) } \\
(\mathrm{n}=47) M(\text { s.d. })\end{array}$ & $\begin{array}{l}3 \text { Months post discharge (T2) } \\
(\mathrm{n}=33) M(\text { s.d.) }\end{array}$ & $\begin{array}{c}\text { Paired samples } \\
\text { t-test } \\
\text { P-value }\end{array}$ & Effect size (Cohen's d) \\
\hline Hope & $26.72(2.81)$ & $25.91(3.66)$ & 0.25 & 0.25 \\
\hline Depression & $20.42(6.84)$ & $20.44(8.92)$ & 0.70 & 0.003 \\
\hline Self-efficacy & $86.60(17.45)$ & $88.03(21.41)$ & 0.90 & 0.07 \\
\hline Self-rated adjustment & - & $6.71(2.60)$ & - & - \\
\hline Life problems & - & $30.18(12.56)$ & - & - \\
\hline \multicolumn{5}{|l|}{ Coping style } \\
\hline Behavioural disengagement & $5.79(1.88)$ & $5.32(1.75)$ & $0.05^{\mathrm{a}}$ & 0.26 \\
\hline Planning & $13.66(2.58)$ & $13.29(2.38)$ & 0.25 & 0.15 \\
\hline Positive reframing & $13.22(2.84)$ & $12.88(3.05)$ & 0.31 & 0.11 \\
\hline
\end{tabular}

$P=0.01)$, life satisfaction subscale score $\left(r_{s}(32)=0.60, P=0.01\right)$ and self-rated adjustment subscale score $\left(r_{s}(32)=0.049, P=0.01\right)$. There was a significant, negative correlation between HS score and life problems subscale score, $\left(r_{s}(32)=-0.55, P=0.01\right)$. There was also a significant, negative correlation between HS score and depression scores $\left(r_{s}(32)=-0.35, P=0.05\right)$.

Utilising Cohen's strength of association criteria, there was a moderately strong relationship between hope and self-efficacy, life satisfaction and self-rated adjustment, such that higher levels of hope were associated with increased levels in these domains. Conversely, there was a strong relationship with hope and life problems, such that higher hope was associated with a lower level of life problems. There was also a moderately strong relationship between hope and depression scores, such that higher hope was associated with lower depression scores.

Hope and coping styles. As above, Spearman's correlation was used to identify the strength of relationships between hope and coping styles at 3 months post discharge. The outcome variables were behavioural disengagement, planning, positive reframing, acceptance, social reliance and fighting spirit. There were significant, positive correlations between HS score and planning subscale score $\left(r_{s}(32)=0.45, P=0.01\right)$, positive reframing score $\left(r_{s}(32)=0.64, P=0.01\right)$, acceptance subscale score $\left(r_{s}(32)=0.60\right.$, $P=0.01)$ and fighting spirit subscale score $\left(r_{\mathrm{s}}(32)=0.52, P=0.01\right)$. There were significant, negative correlations between HS score and behavioural disengagement score $\left(r_{\mathrm{s}}(32)=-0.51, P=0.01\right)$, and social reliance score $\left(r_{s}(32)=-0.37, P=0.05\right)$.

There were moderately strong relationships between hope and the planning, positive reframing, acceptance and fighting spirit coping styles, such that higher levels of hope were associated with a higher level of utilisation of these styles. There were also moderate relationships between hope and the behavioural disengagement and social reliance coping styles, such that higher levels of hope were associated with lower levels of reliance on others and less behavioural disengagement (Table 3 ).

\section{DISCUSSION}

Overall, those with higher hope demonstrated better psychosocial adjustment outcomes than those with lower hope. There were significant relationships indicating that those with higher hope scores had significantly higher levels of self-efficacy, life
Table 3. Spearman's correlation of hope scores with outcomes and coping styles

\begin{tabular}{lc}
\hline Measure & Spearman's Correlation (r) \\
\hline Outcome measures & \\
Depression & $0.35^{*}$ \\
Self-efficacy & $0.54^{* *}$ \\
& \\
Final outcome measures & $0.60^{* *}$ \\
Life satisfaction & $0.49^{* *}$ \\
Self-rated adjustment & $-0.55^{* *}$ \\
Life problems & \\
& \\
Coping style variables & $-0.51^{* *}$ \\
Behavioural disengagement & $0.45^{* *}$ \\
Planning & $0.64^{* *}$ \\
Positive reframing & $0.60^{* *}$ \\
Acceptance & $-0.37^{*}$ \\
Social reliance & $0.52^{* *}$ \\
Fighting spirit & \\
\hline${ }^{*} P 0.05 ; * * P \leqslant 0.01$. & \\
\hline
\end{tabular}

satisfaction, self-rated adjustment and significantly lower levels of depression and perceived problems in their lives. Thus the first hypothesis that a higher level of hope was associated with better psychosocial adjustment outcomes following a $\mathrm{SCl}$ is confirmed.

While causal links cannot be established, these findings suggest that strategies to promote hope in rehabilitation settings may have a positive impact on adjustment outcomes. These findings also confirmed a prior qualitative study, which observed that while at times challenging for rehabilitation professionals, a person's hope to walk again and preparation for living with a mobility disability are not mutually exclusive. ${ }^{18}$ For example, people who understand that their spinal cord lesion is complete and that from a medical perspective there is little hope for recovery are often able to maintain a seemingly contradictory hope to walk again while fully engaging in a rehabilitation program in preparation for life in a wheelchair. Likewise, in the field of palliative care, where the importance of hope is widely acknowledged, many examples of hope in contradictory circumstances can be found. ${ }^{22,41,42}$ Positive illusions, denial, false hope or unrealistic optimism may act as a buffer, which allows people to maintain hope and 
motivation in life. Only at the extreme end of reality distortion is false hope found to be counterproductive. ${ }^{20,43,44}$ Given the relationships between hope and adjustment, it is particularly important that rehabilitation professionals understand the significance of hope in their interactions with clients.

The second and third hypotheses that people with $\mathrm{SCl}$ and higher hope would be more likely to utilise positive coping strategies such as acceptance, fighting spirit and positive reinterpretation and; people with $\mathrm{SCl}$ and higher hope would be less likely to use less effective coping strategies such as social reliance or behavioural disengagement were also confirmed. Participants with higher hope scores demonstrated a significant, positive correlation with the coping strategies; planning, positive reframing, acceptance, and fighting spirit and a negative correlation with behavioural disengagement and social reliance. Conceptually the coping strategies planning and fighting spirit closely align with aspects of hopefulness such as goal setting, problem solving and thinking about ways to achieve desired outcomes suggesting that there may be some overlap in these constructs. Overall, these results indicated that higher hope levels were associated with more adaptive coping styles following a $\mathrm{SCl}$.

This study was informed by Snyder's conceptualisation of hope, where hope is defined as 'the process of thinking about one's goals, along with the motivation to move towards those goals (agency) and the ways to achieve those goals (pathways)'. ${ }^{45}$ In this model, goals are the desired outcomes and provide an anchor for hopeful thinking. ${ }^{25,46-48}$ Pathway thinking is the perception that achievable plans to attain goals can be developed and agency thinking provides the motivation to push through to achieve one's goals. The Snyder model has been widely researched and interventions derived from this model have been tested in a variety of fields such as academic achievement, sport and palliative care. ${ }^{45,49-51}$ Thus, Snyder's hope theory provides a useful framework for understanding and enhancing adaptive ways of coping. In the rehabilitation context, this conceptualisation of hope has the potential to inform clinical interventions to support hope. Goals are the target of rehabilitation interventions and achievement is largely dependent on the capacity of the individual to see the possibilities and push forward to achieve these goals. Further research is necessary to more fully explore the utility of this model to support individuals participating in rehabilitation and positive psychosocial adjustment outcomes.

There was no significant change in any of the variables measured over time. This stability suggests that both a person's capacity for hope and their coping style remain constant, when confronted with substantial life stressors such as SCl. While both hope and coping style are influenced by one's personality traits, evidence suggests that both are responsive to targeted interventions, particularly in the acute phase following injury. ${ }^{52-54}$ However, the interplay between hope and coping is complex. Conceptually hope is identified as playing a moderating role between stressful life events and coping outcomes. ${ }^{2,55}$ It has been suggested that the capacity to sustain coping efforts in the face of intense and sustained stressful circumstances is dependent on hope. 22,56 Thus, effective interventions to support hope are integral to enhance the coping capacity and psychosocial adjustment outcomes for people with $\mathrm{SCl}$. For example, immediately after sustaining a $\mathrm{SCl}$, a person may feel that many of their life goals are unachievable. Rehabilitation staff can play a key role in helping the injured person to re-establish meaningful goals and identify pathways to achieve these goals. In one sense, this is the very core of rehabilitation practice while also effectively helping people regain a sense of control and hope for the future.

On the basis of the clinical experience of the authors, it is suggested that hope and coping capacity may be further challenged in the face of serious and ongoing health and/or environmental difficulties. It has been our experience that even the most positive people can lose hope when it seems the world is stacked against them. For example, sustained financial hardship, which deprives one of access to necessary resources for independence or community participation can deplete hope and coping capacity. Likewise chronic pain may exhaust hope and coping resources. Thus, it is important that hope and coping interventions should include ongoing health services, community support and advocacy to ensure environmental and health factors are addressed. The authors acknowledge the importance of holistic approaches, which includes health, psychosocial and environmental interventions and do not suggest that psychological interventions alone are able to adequately support hope or coping.

Given that one of the aims of rehabilitation is to help people become more confident in managing their condition, it was an unanticipated finding that self-efficacy scores did not change over time. It may be that 3 months post discharge from hospital is not sufficient time for people to consolidate the knowledge and skills gained through rehabilitation into day-to-day living. The initial period following discharge is particularly challenging, as people resume responsibility for self-management without the supports available within a hospital-based rehabilitation program.

The differences between depression levels in the Australian sample and the New Zealand sample were likewise an unexpected finding. This may be a result of the small sample size and requires further investigation.

While this study highlights the correlations between hope, positive adjustment and coping style, further research is required to more fully explore the links between practices to enhance hope (or coping) strength in individuals who are challenged in these areas. To date research into hope interventions has largely focussed on non-disabled populations. In non-disabled populations, hope interventions have been found to be effective in dealing with stress. This study is one of the first to explore the correlations between hope and psychosocial adjustment in a rehabilitation setting. The stresses associated with $\mathrm{SCl}$ are qualitatively quite different from the situations in which hope interventions have been investigated to date and further study of hope-enhancing strategies in the rehabilitation setting is justified.

It may be that building a deliberate culture of hope within the rehabilitation setting is an effective starting point. This would involve considerable effort to cultivate environments and staff attitudes where hope can thrive. The contribution of peer support in building and maintaining hope in rehabilitation should be considered. Peer support may provide positive role models and assist newly injured individuals to identify achievable goals and provide motivation to pursue these goals. The utility of hope theory to develop specific hope interventions, which could be targeted to those most challenged also merits further investigation.

\section{Limitations of the study}

The primary limitation of this study relates to the small sample size, attrition and the non-normal distributions necessitating the use of non-parametric statistical procedures. The sample size was limited by the overall population size and $\mathrm{SCl}$ incidence in Australia and New Zealand. While the numbers are relatively small from a statistical perspective, they do represent a sizable proportion of the people who sustain $\mathrm{SCl}$ in each respective country each year.

This study had a short follow-up period ( 3 months post discharge). The initial hospital rehabilitative episode and the transition to community living post $\mathrm{SCl}$ are frequently identified as a challenging stage in the adjustment process. Focusing hopeenhancing interventions during this phase of the adjustment process has the potential to play a mediating role in the longerterm outcomes. The outcomes may have been different if a longitudinal study over a longer period had been feasible. 
This study makes a substantial contribution to the understanding of the relationship between hope, coping and psychosocial adjustment following $\mathrm{SCl}$. Further research is necessary to fully explore causation and investigate appropriate strategies to enhance hope and coping capacity in those who are struggling in their adjustment processes. It is suggested that future research consider multiple measures of hope to build a more robust understanding of the relationships between hope and coping outcomes.

\section{ACKNOWLEDGEMENTS}

We would like to acknowledge the valuable contributions of each participant, who were experiencing a difficult phase in their lives but gave freely of their time and insights to further our understandings. We would also like to acknowledge the valuable contributions of research assistants: Holly Pellosma, Charmaine Jensen, Julia Bloom and Karen Marshall with data collection and preparation of the manuscript.

\section{COMPETING INTERESTS}

The authors declare no conflict of interest

\section{PUBLISHER'S NOTE}

Springer Nature remains neutral with regard to jurisdictional claims in published maps and institutional affiliations.

\section{REFERENCES}

1 Garske GG, Turpin JO. Understanding psychosocial adjustment to disability: an American perspective. Int J Rehabil Health 1998; 4: 29-37.

2 Kennedy P, Kilvert A, Hasson L. A 21-year longitudinal analysis of impact, coping, and appraisals following spinal cord injury. Rehabil Psychol 2016; 61: 92-101.

3 Lazarus RS, Folkman S. Coping theory and research: past, present and future. Psychosom Med 1993; 55: 234-247.

4 Trieschmann RB. Spinal Cord Injuries: Psychological, Social and Vocational Rehabilitation, 2nd edn, Demos: New York, NY, USA, 1988, pp 345.

5 Kennedy P, Evans M, Sandhu N. Psychological adjustment to spinal cord injury: the contribution of coping, hope and cognitive appraisals. Psychol Health Med 2009; 14: 17-33.

6 Elliott TR, Kurylo M, Rivera P. Positive growth following acquired physical disability In: Snyder CR, Lopez SJ (eds). Handbook of Positive Psychology. Oxford University Press: Oxford, UK, 2002, pp 687-699.

7 Kennedy P, Lude P, Taylor N. Quality of life, social participation, appraisals, and coping post spinal cord injury: a review of four community samples. Spinal Cord 2006; 44: 95-105.

8 Kennedy P, Rogers BA. Anxiety and depression after spinal cord injury: a longitudinal analysis. Arch Phys Med Rehabil 2000; 81: 932-937.

9 Dorsett P, Geraghty TJ. Depression and adjustment following spinal cord injury: a three year longitudinal study. Top Spinal Cord Inj Rehabil 2004; 9: 43-56.

10 Krause JS, Kemp B, Coker J. Depression after spinal cord injury: relation to gender, ethnicity, aging and socioeconomic indicators. Arch Phys Med Rehabil 2000; 81: 1099-1109.

11 Elfstrom M, Kreuter M, Ryde A, Persson LO, Sullivan M. Effects of coping on psychological outcome when controlling for background variables: a study of traumatically spinal cord lesioned persons. Spinal Cord 2002; 40: 408-415.

12 Elfstrom M, Ryden A, Kreuter M, Taft C, Sullivan M. Relations between coping strategies and health-related quality of life in patients with spinal cord lesion. J Rehabil Med 2005; 37: 9-16.

13 Kennedy P, Marsh N, Lowe R, Grey N, Short E, Rogers B. A longitudinal analysis of psychological impact and coping strategies following spinal cord injury. $\mathrm{Br} J$ Health Psychol 2000; 5: 157-172.

14 Kortte KB, Gilbert M, Gorman P, Wegener ST. Positive psychological variables in the prediction of life satisfaction after spinal cord injury. Rehabil Psychol 2010; 55: 40-47.

15 Krause JS, Edles PA. Injury perceptions, hope for recovery, and psychological status after spinal cord injury. Rehabil Psychol 2014; 59: 176-182.

16 Carver CS. You want to measure coping but your protocol's too long: consider the brief cope. Int J Behav Med 1997; 4: 92.

17 Carver CS, Scheier MF, Weintraub JK. Assessing coping strategies: a theoretically based approach. J Pers Soc Psychol 1989; 56: 267-283.

18 Dorsett $P$. The importance of hope in coping with severe acquired disability. Aust Social Work 2010; 63: 83-102.
19 Martz E, Livneh H, Priebe MM, Wuermser L, Ottomanelli L. Predictors of psychosocial adaptation among people with spinal cord injury or disorder. Arch Phys Med Rehabil 2005; 86: 1182-1192.

20 Elliott TR, Richards JS. Living with the facts, negotiating the terms: unrealistic beliefs, denial and adjustment in the first year of acquired disability. J Pers Interpers Los 1999; 4: 361-381.

21 Sommerfield MR, Mccrae RR. Stress and coping research: methodological challenges, theoretical advances and clinical applications. Am Psychol 2000; 55: 620-625.

22 Folkman S. Stress, coping, and hope. Psychooncology 2010; 19: 901-908.

23 O'Connor RC, Connery H, Cheyne WM. Hopelessness: the role of depression, future directed thinking and cognitive vulnerability. Psychol Health Med 2000; 5: 155-161.

24 Lopez SJ, Ciarlelli R, Coffman L, Stone M, Wyatt L. Diagnosing for strengths: on measuring hope building blocks. In: Snyder CR (ed). Handbook of Hope: Theory, Measures and Applications. Academic press: San Diego, CA, USA, 2000, pp 57-85.

25 Snyder CR, Harris C, Anderson JR, Holleran SA, Irving LM, Sigmon ST et al. The will and the ways: development and validation of an individual-differences measure of hope. J Pers Soc Psychol 1991; 60: 570-585.

26 Cheavens J, Gum A, Snyder CR. The trait hope scale. In: Mlatby J, Lewis CA, Hill A (eds). Handbook of Psychological Tests. Mellen Press: Lmaper, Wales, UK, 2000, pp 248-258.

27 Middleton JW, Tate RL, Geraghty TJ. Self-efficacy and spinal cord injury: psychometric properties of a new scale. Rehabil Psychol 2003; 48: 281-288.

28 Middleton JW, Tran Y, Craig A. Relationship between quality of life and self-esteem in persons with spinal cord injuries. Arch Phys Med Rehabil 2007; 88: 1643-1648.

29 Miller SM. The measurement of self-efficacy in persons with spinal cord injury: psychometric validation of teh moorong self-efficacy scale. Disabil Rehabil 2009; 3112: 988-993.

30 Crewe NM. Gains and losses due to spinal cord injury: views across 20 years. Top Spinal Cord Inj Rehabil 1996; 2: 46-57.

31 Krause JS. Longitudinal changes in adjustment after spinal cord injury: a 15-year study. Arch Phys Med Rehabil 1992; 73: 564-568.

32 Krause JS. Changes in adjustment after spinal cord injury: a 20-year longitudinal study. Rehabil Psychol 1998; 43: 41-55.

33 Radloff LS. The CES-D Scale: a self report depression scale for research in the general population. Appl Psychol Meas 1977; 1: 385-398.

34 Cook KF, Kallen MA, Bombardier C, Bamer AM, Choi SW, Kim J et al. Do measures of depressive symptoms function differently in people with spinal cord injury versus primary care patients: the CES-D, PHQ-9, and PROMIS $-\mathrm{D}$. Qual Life Res 2017: 26: 139-148.

35 Coyle CP, Lesnik-Emas S, Kinney WB. Predicting life satisfaction among adults with spinal cord injuries. Rehabil Psychol 1994; 39: 95-112.

36 Devins GM, Orme CM. Center for epidemiologic studies depression scale. In: Keyer DJ, Sweetlands RC (eds). Test Critiques. 2. Westport Publishers: Kansas City, MO, USA, 1985, pp 144-160.

37 Rintala DH, Young ME, Hart KA, Fuhrer MJ. The relationship between the extent of reciprocity with social supporters and measures of depressive symptomatology, impairment, disability, and handicap in persons with spinal cord injury. Rehabil Psychol 1994; 39: 15-27.

38 Kennedy P, Taylor NM, Duff J. Characteristics predicting effective coping outcomes after coping effectiveness training for patients with spinal cord injuries. J Clin Psychol Med Settings 2005; 12: 93-98.

39 National Health and Medical Research Council. The National Statement on Ethical Conduct in Human Research (Canberra, 2007).

40 Cohen J. Statistical Power Analysis for the Behavioural Sciences, 2nd edn, Lawrence Erlbaum Associates: Mahwah, NJ, USA, 1988.

41 Chi GC. The role of hope in patients with cancer. Oncol Nurs Forum 2007; 34: 415-424.

42 Irving LM, Snyder CR, Crowson JJ Jr. Hope and coping with cancer by college women. J Pers 1998; 66: 195-214.

43 Elliot TR, Witty TE, Herrick S, Hoffman JT. Negotiating reality after physical loss: hope, depression, and disability. J Pers Soc Psychol 1991; 61: 608-613.

44 Snyder CR. 'False' hope. J Clin Psychol 2002; 58: 1003-1022.

45 Snyder CR, Shorey HS, Cheavens J, Pulvers KM, Adams VH, Wiklund C. Hope and academic success in college. J Educ Psychol 2002; 94: 820-826.

46 Snyder CR (ed). Handbook of Hope: Theory, Measures and Applications. Academic Press: San Diego, CA, USA, 2000.

47 Snyder CR. Hope theory: rainbows in the mind. Psychol Inq 2002; 13: 249-275.

48 Snyder CR, Rand KL, Sigmon ST. Hope theory: a member of the positive psychology family. In: Snyder CR, Lopez SJ (eds). Handbook of Positive Psychology. Oxford University Press: Oxford, UK, 2002, pp 257-276.

49 Snyder CR. Hope for the journey. In: Turnbull AP, Patterson JM, Behr SK, Murphy DL, Marquis JG, Blue-Banning MJ (eds). Cognitive Coping, Families, and Disability. Paul Brookes Publishing Co: Baltimore, MD, USA, 1993, pp 271-286. 
50 Snyder CR, llardi S, Michael ST, Cheavens J. Hope theory: updating a common process for psychological change. In: Snyder CR, Ingram RE (eds). Handbook of Psychological Change: Psychotherapy Processes and Practices for the 21st Century. John Wiley \& Sons: New York, NY, USA, 2000.

51 Snyder CR, Sympson SC, Michael SE, Cheavens J. Optimism and hope constructs: variants on a positive expectancy theme. In: Chang EC (ed). Optimism \& Pessimism: Implications for Theory, Research, and Practice. American Psychological Association: Washington, DC, USA, 2001, pp 101-123.

52 Craig AR, Hancock K, Chang E, Dickson H. Immunizing against depression and anxiety after spinal cord injury. Arch Phys Med Rehabil 1998; 79: 375-377.
53 Kennedy P, Duff J, Evans M, Beedie A. Coping effectiveness training reduces depression and anxiety following traumatic spinal cord injuries. $\mathrm{Br} J$ Clin Psychol 2003; 42: 41-52.

54 Mehta M, Whyte E, Lenze E, Hardy S, Roumani Y, Subashan P et al. Depressive symptoms in late life: associations with apathy, resilience and disability vary between young-old and old-old. Int J Geriatr Psychiatry 2008; 23: 238-243.

55 Valle MF, Huebner S, Suldo SM. An analysis of hope as a psychological strength. J Sch Psychol 2006; 44: 393-406.

56 Folkman S. Positive psychological states and coping with severe stress. Soc Sci Med 1997; 45: 1207-1221. 